\title{
Journal of Astrophysics \& Aerospace Technology
}

\section{Solar Eclipses in the Outlook of the Slavs}

\section{Prokofyev A*}

KITION Planetarium \& Observatory, Kiti, Larnaca, Cyprus

*Corresponding author: Alexandr Prokofyev, KITION Planetarium \& Observatory, Ammochostou 9, Kiti, 7550, Larnaca, Cyprus. Tel: +357 99037440; E-mail: prokophyev@yahoo.com

Rec date: Jul 1, 2014, Acc date: Jul 26, 2014, Pub date: Aug 15, 2014

Copyright: ( 2014 Prokofyev A. This is an open-access article distributed under the terms of the Creative Commons Attribution License, which permits unrestricted use, distribution, and reproduction in any medium, provided the original author and source are credited.

\begin{abstract}
The article provides an overview of descriptions of total solar eclipses in different literature forms, rites and toponyms of Slavs. It is shown that the solar eclipse had a prominent role in the worldview of the tribes. Explanations of some terms of Slavic outlook are given with suggestions for the correct terminology. A program for further investigation in Slavic and other people's culture is proposed.
\end{abstract}

Keywords: Total solar eclipse; Archeoastronomy; Mythology; Slavs; Akhet; Myth of creation of the world; Myth of end of the world; Dragon slayer; Tales

\section{Introduction}

The total solar eclipse is the most impressive, memorable and indelible among all astronomical phenomena. For no apparent reason, and without warning, the sky darkens, the air becomes cooler, the sun disappears, and at that moment the sun disappears and a black hole appears in its place, surrounded by a pearly glow, stars flare and no one knows how long it will last. The silence comes, which is not broken even by the cry of a rare bird, and then suddenly and unexpectedly the first ray of the sun appears, the sun is visible again, and everything is repeated in reverse order. This happens from century to century, since the dawn of human civilization. It is difficult to imagine humans not including in their perception of the world this grand cosmic spectacle, where people are curious, but powerless contemplatives.

A contemporary investigator of ancient astronomy, Aymen Ibrahim [1] (Alexandria planetarium, Egypt) found that the myth of creation in ancient Egypt describes in detail the phases of a total solar eclipse. For clarity let us highlight the main results.

The myth states that at the beginning there was Chaos, represented by the goddess Nun - the world's oceans, from which rose a lump of land. From here originated the Benben stone. On this stone, a lotus bloomed, in which there was an egg. From this egg, the god of the Sun, $\mathrm{Ra}$, was born. Next, through a series of births of other gods the world and people were created. As a result, a pharaoh is considered the grand-grand-grandson of Ra. There are various versions of the myth, but generally they are not essential for next consideration.

Aymen explained that the stone Benben ('ben' means 'shine') is a partial phase of the solar eclipse, when instead of the full disk in the sky, a 'crescent' shines. The egg in the center of the lotus is a description of the round black 'hole' in the place of the sun, in the frame of the solar corona. In years of maximum sun activity the corona looks disheveled with multiple petals, and practically resembles a lotus flower (Figure 1). And without any allegory, the myth then reports that the Sun appears out of the egg. In order to make this interpretation viable Aymen needed to make one correction.
Character 'Akhet' (Figure 2) should be translated as 'eclipse' instead of 'horizon'. Then the next well-known text obtains a simple explanation. During the advance of the eclipse (former translation: after sunset at the horizon) $\mathrm{Ra}$ joins the fight against the forces of darkness, crocodiles, snakes and so on. As a result of the struggle he dies. Later, $\mathrm{Ra}$ is reborn again and appears in the sky at the end of the eclipse (former translation: after the appearance over the horizon, at sunrise). Thus, until recently, this was perceived as a text description of the daily order. This happens with the Sun god every night. In the interpretation of the text by Aymen it is one of the earliest descriptions of the total solar eclipse by the eyes of an ancient observer. But the new interpretation gives different meaning to the text. It is a description of an extraordinary, rare phenomenon worthy to note down. Observers witnessed the dying of the Sun god and his miraculous revival. In this approach, a deadly struggle of the Sun god and his death are observed phases of a solar eclipse.

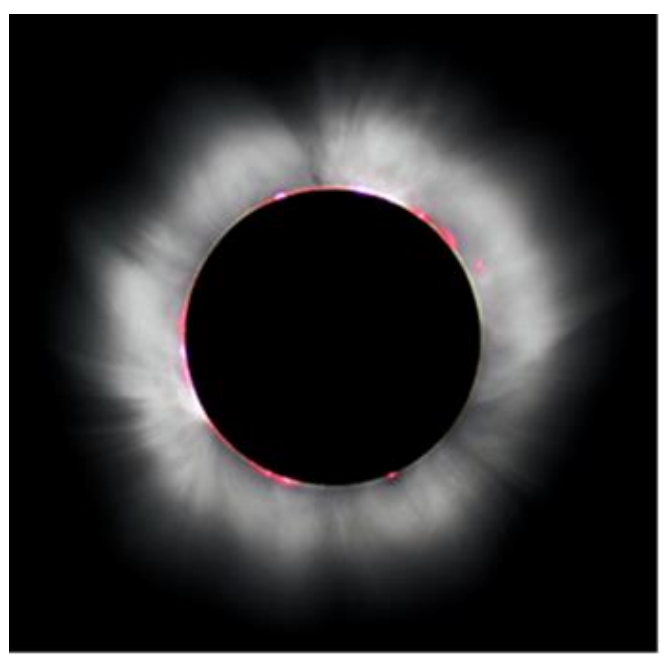

Figure 1: Solar corona. Photo taken by Luc Viatour

The solar eclipse is a rare phenomenon, and the story of its observation has been transmitted to subsequent generations. In addition, each new observation resulted in a more correct description, 
Page 2 of 9

crystallizing the main details and giving a clear representation of the sequence. In this way a collective story of the death and birth of the sun during an eclipse was created.

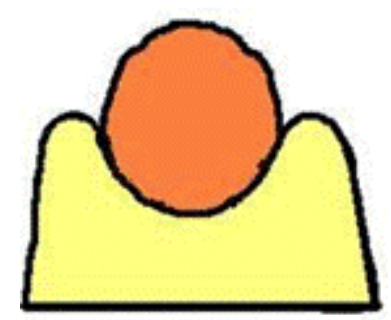

Figure 2: Character Akhet

This point of view suggested by Aymen is very productive. For example, it gives absolute dates for some events of the $2^{\text {nd }}$ millennium $\mathrm{BC}$, confirmed longest reigning pharaohs etc. The reader is referred to article [2], where fully traced absolute dating events of the New Kingdom are discussed.

One more interesting conclusion is important for further consideration. Recall that the grand-grandfather of a pharaoh is the Sun god himself. People observed that Ra dies and is always reborn during the eclipses. For this reason, it is natural to believe that the pharaoh has an immortal soul which after his death will be reborn and reunited with the other gods.

So the total solar eclipse is reflected in the three main ideas of Ancient Egypt: the myth of creation and end of the world, the myth of the solar god's death and rebirth after the victory over darkness, and the idea of immortality of the soul of the country leaders because of their solar nature.

Thus, Aymen Ibrahim fully justified all aspects of the solar eclipse in the ideology of Egyptians. This complex of myths was knowledge that time was not separate from the rest of the world. It was spread to other peoples, first of all to the highly developed state in Mesopotamia. Soviet linguist Illich-Svitych [3] made the surprising discovery that in the ancient Indo-European language there are Semitic borrowings from ancient Mesopotamia. This allowed Vyacheslav Vsevolodovich Ivanov and Tamaz Valerianovich Gamkrelidze to substantiate that Indo-Europeans have a West Asian origin [4]. Starting from the $3^{\text {rd }}$ millennium BC they began their advance, and resettled from the Pacific Ocean to Iceland. Protoslavics is a branch of Indo-Europeans. In the $6^{\text {th }}$ Century BC they divided in separate tribes, leaving artefacts the culture of Korchak type. Protoslavics were mostly farmers and settled preferably along rivers. They lived in clans, where family ties were considered for up to six generations, so there were up to 100 people in one settlement. Even many centuries later, up to the 5-6 century $\mathrm{AD}$, Slavs were generally a homogeneous culture. A vast resettlement of the Slavs occurred in the 5-6 century $\mathrm{AD}$, which ended in the creation of many peculiar languages. In the 9-10 century AD Slavic states appeared: Great Moravia, Croatia, Polyansky (Polish) principality, the Bulgarian state and the Russian state. The creation of states brought a new type of settlement - the town, stimulated the development of writing and required the centralization of power. Overall, this resulted in a crisis of the previous way of life, and as a way out of it - in the Christianization of the Slavs. Eastern Slavs lived more apart. The influence on them of the Finns and other neighbors is undeniable, however slight. Even the adoption of Christianity due to such identities included pagan worldviews and rituals. As a result, the Eastern Slavs, more than others, preserved archaic elements that has created the perfect stage for researchers. The study of Western and Southern Slavs also identifies archaic forms, but there are more layers of late periods on them. It seems that the best source for studying Slavs, their culture and worldview are written sources. However, these are scarce. Nowadays, there are several chronicles and a few inserts from copyists (called glosses). In addition, all sources consist of later Christian works that present the material both sketchy and from a position of humiliation of pagan beliefs. In fact, folklore acquires the same significance as the Christian chronicle for the study of the Slavic culture.

In the history of world literature, the 19 century $\mathrm{AD}$ occupies a special place. During that period, the peak of collection, processing and publication of folklore all over the world: songs, legends, myths, fairy tales, etc. took place. To name just a few, are the collection of tales by the Brothers Grimm in Germany, the collection of Indian tales in homes of governors of India, and the Finnish Kalevala composed by Lönnrot. In the Russian Empire, Russian folk tales were collected by Afanasyev as well as Bazhov who as a boy heard the tales and then wrote them down.

In this article, a vast spectrum of remains of the original worldview of Slavs is considered step-by-step. It will be shown that total solar eclipses interweaved in the main myths. Literature forms are the main sources of Slavic mythology; therefore, written songs, tales, riddles and toponymic names are discussed.

All translations of resources from Slavic languages and ancient Russian into English are conducted by the author, even in the cases where texts are known in English translation already. This is done in order not to lose details, which are essential for consideration.

\section{Myth of creation}

After the Christianization of Slavs, almost all their pagan culture was lost or transformed and woven into the doctrine of Christianity. An apocryphal "On the Sea of Galilee", which is accepted to be no earlier than the 16 cent., is preserved in several lists [5] and has deep pre-Christian ideas of creation. The story of the creation of the world is carried out not in a Christian manner, though the protagonists there are God and Satan. Almost in the same style, the creation of the world remained in carols from western Ukraine. The only difference is that the participants of creation were left the same, no replacement of them into Christian ones occurred. Vladimir Gnatiuk published in Lvov (the Russian Empire town that time) in 1914 "Carols and schedrivkas" in one of the ethnographic collection of the Scientific Society named after Shevchenko [6].

In this collection, the motif of creation is represented as follows

When there was no world

Blow up; blow the Lord with the Holy Spirit on the land!

There were no sky, no land,

But there was a blue sea only,

\section{And a green sycamore was amidst it.}

The pre-Christian creation of the world is described here clearly. It is important that originally there was a blue sea. As we remember, in 
the view of the ancient Egyptians at the beginning there was Chaos, also represented by the ocean in the sky. And if the similarity here is still viewed as mere coincidence, the following folk resource from the same book adds more details. Here a bird goes to the bottom of the sea.

\section{Let's draw down to the bottom of the sea}

Let's get petty sand:

We shall seed the petty sand:

And the black soil will become for us.

Let's fish out a golden stone,

We shall seed the golden stone:

And for us will become the clear sky,

\section{Light sun, clear moon,}

\section{Clear moon, petty starlets}

Ancient Egyptian mythology is not a single entity. Myths of different names in different parts differed from each other, and they are varied in the same location over time. The Bennu bird appears in other versions of the myth of creation of an island in the ocean of heaven. The cry of the bird broke the primeval silence, and this cry determined what will be and what will not be born in the world.

In any case, the Ukrainian carol describes the same sequence of birth of the world. Soil comes from the ocean, a golden stone appears on it, and the sun appears from the stone. The creation of the moon and stars is a later layering. Also, it is noteworthy to mention the golden stone which is analogous to the ancient Egyptian Benben stone. The name of the stone means more than just to 'shine'. For example, Queen Hatshepsut (New Kingdom) erected two obelisks at Karnak. The top of each obelisk represented the Benben stone and was in the form of a right pyramid covered with electro. Following the Aymen interpretation, the gold color is legitimate - the Benben stone is a partial phase of the solar eclipse, and the glowing 'crescent' of the sun is of gold color. Exactly the same sequence is followed in the Ukrainian folklore, where after the appearance of the golden stone the sun was born.

The following aspects of creation were found in the "Great Russian Spells" collected and published in 1869 by Maykov. Following is a spell against snakes:

Then white stone lay on the sea on the Ocean on the Buyan Island. Skorpeya snake sits on this stone. "Hey, thou art, the snake skorpeya, I come to thou with needs." - "Which's one?" - "Find that snake which bitten a servant of God" (John Doe). - "I said, I will not." - "And I'll kill thou by thunder." - "And I'll hide from the thunder in the ground." "And I'll sprinkle into your ears fierce potion." [7]

Two parts associated with the solar eclipse are present in the spell: both the myth of creation and the myth of the fight of the solar hero with the serpent. The second one will be considered in chapter 3. In relation to the myth of creation, again there is an island in the ocean, and a white stone on it. What is this stone? In tales and other spells this stone is given various names. These are white stone, whiteinflammable stone, Alatyr-stone, Latyr and all stones stone, all stones father. The Island Buyan itself takes proud place in the Slavic worldview. It is in the center of the world, the world tree is growing there and Alatyr-stone is on it.
These lines of the spell demonstrate almost complete agreement with the ancient Egyptian myth. In the ocean [in heaven] there is an island with the Benben stone. It is on this island where the battle of the solar hero with the forces of darkness takes place (see chapter 3 ). The island is very important for this reason, and to be in the center of the universe in the Slavic worldview is natural for it. The Slavic world tree is placed on the island. Sometimes it is specified that this is an oak or sycamore tree (seldom, though see the Christmas carol above). The appearance of oak together with the primary stone in the myth is not a coincidence. Ivanov and Toporov [8] demonstrated the equivalence of the word 'oak' and 'stone' in the archaic language, the very names which they associated with the attributes of a hero Dragonslayer. In light of the current reconstruction, it is possible to specify the meaning of the name Alatyr. Until recently in the study of Slavs, the name Alatyr derives from 'amber'. This version was first proposed by Nadezhdin [9] (in Russian these two words the stone 'Alatyr' and amber - 'yantar' sound similar). Nadezhdin believed that Alatyr is amber for a bright golden color and flammable properties [9]. Now it looks like Alatyr is not similar to amber. Its characteristics - white, especially white-inflammable - indicates that the origin comes from 'shine', similarly to the Benben stone. This reconstruction gives a different and more natural interpretation of the word 'Alatyr'. It is derived from the word 'light'.

In Belorussia, for more than one decade, Romanov [10] collected Belorussian songs, riddles, tales and other folk literary forms. His work "Belorussian Collection", published in many volumes at the turn of the 19 and 20 centuries, has become a rich source for research, not only of Belorussian Slavs, but also of all the pre-Christian Slavs. The volume devoted to spells, the Apocrypha and spiritual poems, provides the following update on the Island Buyan:

On the sea, on the coast, on a stone, on a height, a green willow (variant sycamore) stays. On that willow there is a gold nest from the black fleece, the snake Shkuropeya Praskoveya lives there.

Here two important characteristics are given - golden and black colors and a snake. The solar corona was described with these colors in the Egyptian myth of creation (egg and lotus). During the eclipse, Ra fights the forces of darkness which are personified in particular in the serpent Apop. He dies during the fight, but then rises and conquers darkness. Therefore, that the snake Shkuropeya Praskoveya resides near the site of the fight, it seems correct from the position of the current reconstruction.

This sequence is preserved remarkably well in the tales about Koschej the Deathless who was substituted in the Polish folklore into a snake or chorts. Let us consider a typical description of his death. It is located in the ocean on the same island Buyan, in the neighborhood of an oak - the same world-tree, in the egg. For example, in the Afanasiev collection of Russian folk tales [11]:

"There is an island on the sea on the ocean, the oak stands on the island, a chest is buried under the oak, a hare is in the chest, a duck is in the hare, an egg is in the duck, and in the egg there is my death."

The Brockhaus and Efron Encyclopedic Dictionary, published in the period 1890-1907, reported "If crush the egg - Koschej immediately dies." In accordance with the interpretation of the solar eclipse, when the sun appears the egg vanishes, hence, along with the destruction of the egg the snake is killed. Therefore, we can say that the Polish version of the tale retained more ancient features, the introduction of Koschej happened later. The word 'koschej' is of Turkic origin and means slave, prisoner, and younger prince. The Slavs, before 
Page 4 of 9

Christianization, considered the prisoners first of all as the slaves that practically identify the first two meanings. The last one - the younger prince - most possibly appeared later. Thus, it is very simple to substantiate the riddle how Koschej became deathless, if his death was in the egg. During the eclipse the negative character dies at the very moment when the egg disappears in the sky. But during the next eclipse the fight will be repeated, thereby observations indicate his immortality. Van der Waerden, studying astronomical texts on clay tablets and papyrus, showed that ancient people had skills to predict lunar eclipses, but could not foresee the solar ones. Even the successful prediction of a solar eclipse by Thales in a later period was proved to be an accident, and not the result of the level of science [12]. Therefore, all that was known at the time of resettlement of the IndoEuropean tribes were conditions for an eclipse, but whether it would happen remained unknown. It was known that these conditions occur regularly, and that solar eclipses happened. These gave ideological underpinnings to assume that this war will again take place in the future. Thus the serpent became deathless, though its death is in the egg.

\section{Myth of the end of the world}

In Slavic culture the solar eclipses were considered as the end of the world. Similarly to ancient Egypt, in the middle Ages in Russia eclipses, above all, installed fear in the population. In the annals of 1230 it reads:

"The sun was crescent ... and it was the great fear and trembling on all, and people becoming confused and terrified, and despairing life, fancied that the end of the world to come" [13].

Note that this is a description of a partial eclipse only. This quote is very revealing. Although between this and the time of appearance of ancient Egyptian myths of creation and the end of the world, some thousands of years have passed, the awe of the eclipse by ancient and medieval people remained the same. The idea that after the eclipse the end of the world will occur and everything will return to the primitive ocean in heaven is preserved, for example, in the Slovak legend, published by Karel Erben. He was one of the most important collectors of folklore in the Czech lands in the 19 century. This legend is given in Russian by Afanasev [11]:

"In ancient times, the land was empty; nothing was on it - just a stone. Regretted that God and sent his cock, let he fertilize the earth. The rooster sat in the cave and laid a wonderful egg from which expired seven rivers; they flooded the plains, and soon all around turned green, flowers blossomed and all was filled with all sorts of fruits; without worries, people lived happily in that paradise. The rooster of God set high in the sky and every day proclaimed to mortals: when they have to wake up from sleep, when to work and when to start their meal. Finally the people tired of incessant crowing of the cock; "We do know when and what to do!" the people said, and prayed to God to free them from the hectic bird. And the rooster of God disappeared from the sky, and the same time the old order of life disturbed, the illness and violence came. Madness possessed people; they went to the wonderful egg and began to throw stones at it. The egg broke with thunder, and so much water hit out of it that soon the whole human race perished. Paradise filled with water, became one large lake" [14].

The beginning of the creation in the cited legend is the same as in ancient Egypt, only the first phase is omitted, when stone appeared in the ocean of heaven. A miraculous egg appears on this stone. And soon a rooster sits in the sky. The image of the rooster represented the sun itself. During a solar eclipse the sun disappears in the sky, and with the fear people have ruined the egg, and the world is drowned in the primary ocean. Here the creation of the world and its death are nonChristian, so the inclusion of the god and paradise in the legend is a later layering. Moreover, the world order is created and maintained by the Sun, which is in full accordance with the ancient Egyptian representation.

Generally speaking, the image of the rooster abuts the image of the Phoenix. Already in the Old Kingdom of Egypt, the Phoenix (Bennu bird) became associated with Ra. The earliest description of a solar eclipse was found by Aymen in one of the Texts of the Pyramids. Aymen interpreted the Phoenix as a solar corona [15].

One of the earliest descriptions of the Phoenix in Russian,

"That bird is in his nest by himself, he has neither befriend, no has the children, but resides in his nest only... But when he becomes old, takes off to the height and gets the heavenly fire, and so descending fired up his nest, and also himself burned but out of ashes of his nest again is reborn" [16]

reflects the main idea: the sun during an eclipse dies and is reborn from the ashes again. Ash could be associated with darkness, coming during an eclipse.

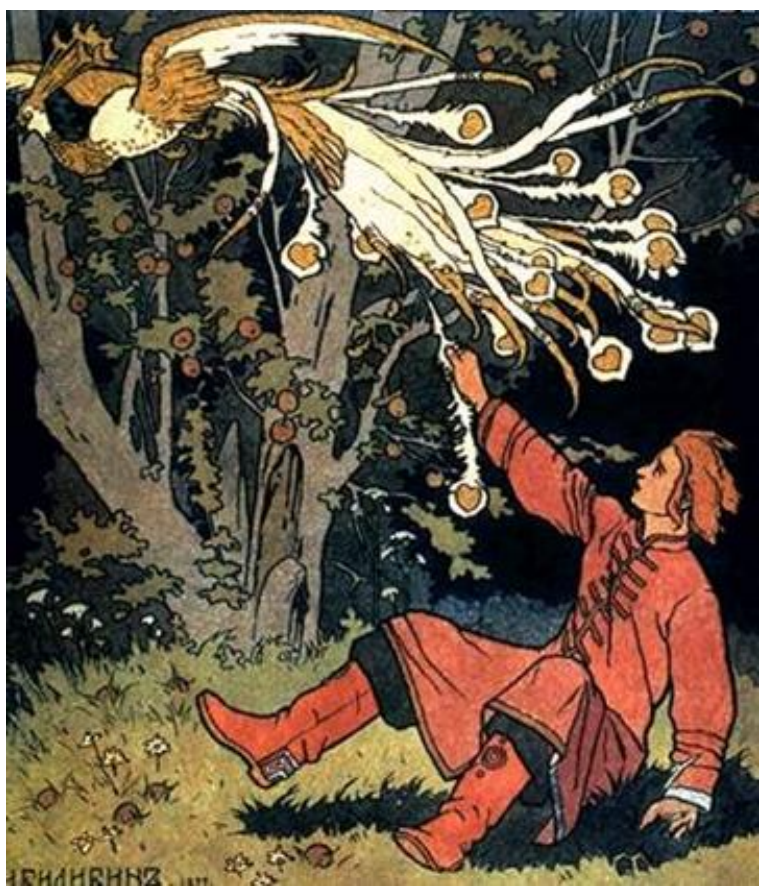

Figure 3: I. Bilibin. Prince Ivan and the Firebird

In Slavic folklore, the Phoenix has changed. It is found in fairy tales as the Firebird (Figure 3). Firebirds have no longer constant resurrection, the intense heat and bright glow of them is preserved only. In the cited legend, the Phoenix was transformed into a rooster where he entirely revealed his role as a support of the universe. This image survived till nowadays in riddles. These are riddles from Little Russia about the sun 
"Stands oak-old oak, on oak there is a bird-revolver; no one can obtain it neither the king nor the queen" or "sits a rooster on a pussy willow, lets down pigtails to the ground."[17]

The proposed reconstruction interprets them as the sun on the world tree; the tree grows at the Island Buyan. In the second one, the sun is directly named a rooster. The first of them has a noteworthy epithet. What could a bird-revolver mean? Since the whole complex ocean-island-world tree-Sun associates with the solar eclipse, then the bird-revolver means a bird that always dies and is reborn, the Phoenix.

\section{Dragon slayers}

The myth of the fight of the solar hero with the dragon takes the main place in the Slavic world, but nowadays it is known in the fragments of folklore. As archaeologists recreate the original contour of the vessel by fractions, so do modern scholars by such pieces of folklore restore the original outlook of the Slavs. This myth is most fully restored as the fight of Perun with Veles, the God of Thunderstorm with the Serpent. Veles the serpent is most vividly preserved in Czech culture. In the rest of the Slavs world, over time he became associated with fertility and as a protector of cattle.

Myth in its pure form, after Christianization and many centuries of struggle against paganism, has unfortunately not survived. Therefore, it has been reconstructed in the above mentioned work by Ivanov and Toporov [8]. Most likely, as a general overview, the myth represents the following sequence. The God of Thunder is located above and below is the Serpent in the waters or in the roots of the world tree or near a stone. During its persecution by the God of Thunder, the Snake consistently hid in a cow, a horse, a man, a tree, a rock, and water. After the murder of the Snake, rain, water, and rivers appear. It is believed that the immediate precursor of this myth is a myth of antagonistic struggle of the Sun with the Serpent. "In the latter case, could be recognized archaic those Lithuanian and Belorussian texts where a word that could mean the God of Thunder acts only in the meaning of the tool of God of Sun. This reconstruction correlates with interpretation of the fight as a description of the total solar eclipse excellently. And the hypothesis that in the earliest variant was the Sun is totally proven by this interpretation.

In a later period, Perun was replaced, for example, by a blacksmith, by other folk heroes, and with Christianization by God, Elijah the prophet, or St. George (Figure 4). In the same way the Snake was modified into Gorynych, Solovey the Robber, and the chort (Christianization). For example, in the Belorussian epic, osiloks (heroes) fight with the Snake, then one of the heroes Ilya overcomes the Snake with a miraculous weapon. In the Great Russian epic, a hero with the same name Ilya fights not with the serpent, but with Solovey (the word means 'nightingale') [18]. The researchers believe that the word 'Solovey' is a replacement for the name Veles, when its very pronunciation was a taboo. That is why the Great Russian epic cycle about Ilya Muromets includes as the main story the Serpent fight as well as the above mentioned Belorussian variant. The solar eclipse interpretation proves this statement. Now it becomes obvious that the Belorussian version is the oldest. The second hero - Dobrynya Nikitich fought with Zmey Gorynych [19], and Alyosha Popovich prayed for a threatening cloud to wet the paper wings of Tugarin Zmeyevich [20]. Thus, the fight with Serpents of the central three heroes from the Great Russian epic reflects the fight of Ra with the serpent Apop during a solar eclipse [21]. Thus, all of the heroes have a solar origin.

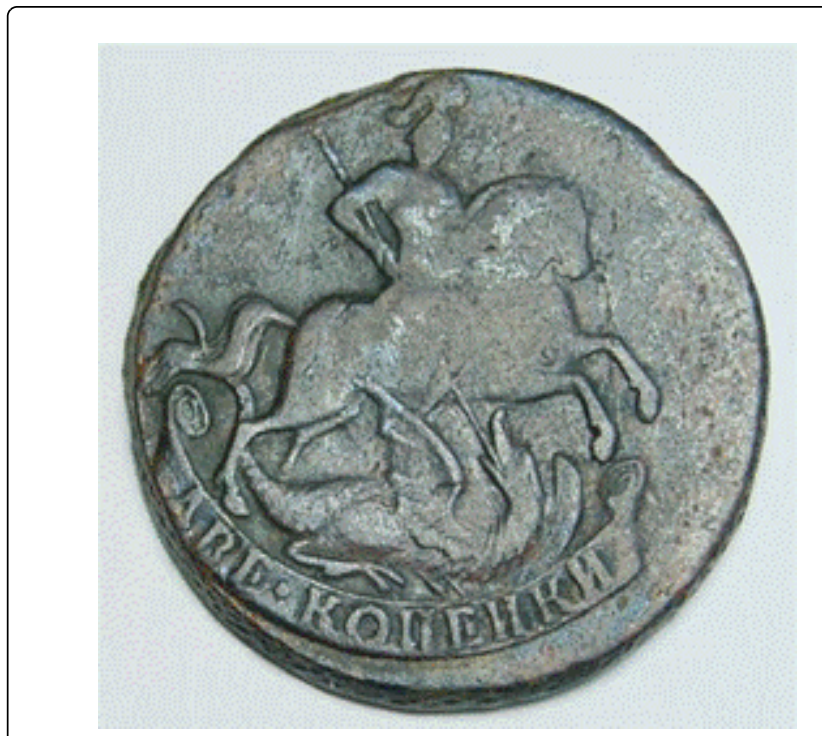

Figure 4: St. George slaying the serpent. Russia 2 kopecks 1758, Credit: astronomic coins collection, Dnepropetrovsk Planetarium

There is the same motif in the above quoted spell against snakes (chapter 1) - "And I'll kill thou by thunder." Here thunder is a weapon in the fight of the god with the serpent.

Let's have a detailed look how the solar eclipse description is intertwined in Russian folk tales. The fairy tale 'Ivan Bykovich' [22] is good for the purpose. Initially, after the birth of heroes

"The boys started to grow by leaps and bounds, as good dough rises on leaven so they are drawn up."

As we identify heroes with the Sun, such rapid growth after their birth could correspond to the appearance of the sun after the totality. For the Sun 'grows' really fast, actually up to one hour or a bit longer, it is in good correlation with the characteristic time of dough rising. Then in the fairy tale a huge stone appears. Ivan Bykovich

"came to the stone and so moved it by his foot - stone nay rumbled and rolled to the other side of the garden and broke all sorts of trees. Under that stone a cellar opened, in the basement there were three heroic horses, harness for battle hanged on the walls: there are for good fellows to stroll about!"

This stone in our reconstruction can be attributed to Alatyr under which there are wonderful items. And again the same motif of obtaining wonderful weapons originally at the Island Buyan is present. Only with those weapons, one can overcome the dragon.

Before the fight on the Kalinovy bridge over the river Smorodina to his $\operatorname{dog}$

"says Chudo-Yudo six-headed:" What art thou, dog meat, stumble for, you crowquill, tremble, and you, Dog-wool, bristled? Do you think Ivan Bykovich is here? So he, the good fellow, not yet born, but if was born, he does not fit to a war: I'll set him on one hand and by another slam - only wet place will be!"

"Ivan Bykovich jumped out: "Do not boast the Evil! Not catching clear falcon it is early to pinch feathers; not trying a good fellow, no 
Page 6 of 9

neediness to blaspheme him. And let's better to try forces: who overcomes, let he boast."

Here the beginning of the fight of the Sun with the dragon is described. It is worth noting the comparison of a good fellow with a clear falcon. In ancient Egypt, the pharaohs had god Horus - a falcon, as their direct ancestor. In the light of the interpretation of the dragon fight as a description of the solar eclipse new explanations of 'Kalinovy Bridge' across the 'river Smorodina' are drawn. These two terms are almost always found in fights with dragons. Experts still do not agree on the meaning of the pair. A leading researcher of Russian fairy tales and tales of the world, Propp [23], wrote: "Kalinovy Bridge - the everlasting item in fairy tales. To explain it I will not undertake, except to say that the river is usually a kind of boundary between the worlds". Such pessimism is justified, since there are several interpretations of these terms. As rightly pointed out by Propp [23], it was difficult to choose a suitable one. In one version, Kalinovy Bridge takes its origin from the Russian word 'kalit' ', 'to heat hot'. The name of the fiery river Smorodina is connected with the word, which already in the 11 cent. $\mathrm{AD}$ was used in the sense of "stink, strong stuffy, smelly, suffocating smell, fumes, stinking spirit, esp. burnt. Smorodny - adj. stinking, smelly, smoked from fatty burnt" [24]. As a result, the fight takes place on a red hot bridge over the stinking river of fire.

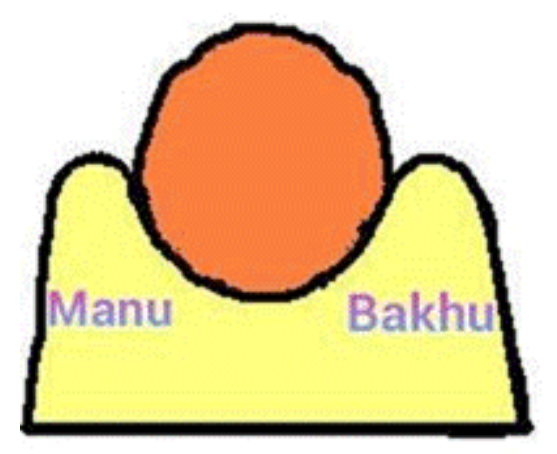

Figure 5: Mountains Manu and Bakhu in the hieroglyph Akhet

As is proposed in this article, the solar eclipse interpretation makes this version of the explanation of the names of the bridge and the river most plausible. Moreover, it is appropriate to suggest that the Russian word 'Smorodina' could be quite close to Polish 'smok' - dragon. In this case the name of the river indicates the Dragon directly. The proposed version is only an assumption, the truth may be deeper. This is one more conclusion of this model which could be researched on the phonetic level in the future. Thus, the fight takes place on a site quite appropriate for a total eclipse: near the red hot bridge on the Snake River. What does the bridge connect? We can suggest two mountains Manu and Bakhu in the hieroglyph Akhet [1], between which the Serpent waits for the Sun (Figure 5).

When the hero fought with the most powerful Chudo-Yudo, he could not overcome him alone, and at the last moment only outside assistance helped him win:

"Ah! - says Chudo-Yudo, - you live by deception; you have a help." The horse of the hero came running, began to beat him by hoofs; and Ivan Bykovich meanwhile climbed out of the ground, dodged and cut off fiery finger of Chudo-Yudo. Then let him cut down heads, knocked down all up to a single, cut the trunk into small pieces and threw all in the river Smorodina."

Our reconstruction dictates to expect in this episode the hero's death, his resurrection and victory. In practice the death is substituted by knocking the hero deep in soil, his resurrection by climbing out of the ground, and victory only is shown completely. After the victory, Ivan Bykovich was blown by trickery into the dungeon of an old man. This visit to the dungeon indicates that the hero died and it proves that the death was substituted in the tale.

The old man locked ships in oak.

"Ivan Bykovich came to the oak, hits it with club countless times and orders: "Everything that is in comes out!" Released the first ship; Ivan Bykovich came on board and shouted: "All follow me!" - and went on his way. After driving a bit, looked back - and saw a countless force of ships and boats! All praise him, all thanks."

The Indian Rig Veda describing the fight of the Solar god Indra with the serpent Val often mentioned the releasing of water, cattle and people from the rock after the victory. For example, one hymn to Indra describes him [25]:

"Who slew the Dragon, freed the Seven Rivers, and drove the kine forth from the cave of Vala, Begat the fire between two stones, the spoiler in warriors' battle, $\mathrm{He}$, O men, is Indra."

Though the presence of total eclipses in Rig Veda as well as in other resources of Indo-European cultures is a productive theme for further investigation, this hymn itself is very prominent. As was discussed earlier, in the ancient Indo-European language 'oak' and 'stone' sounded the same, and the releasing of the ships and people from the oak in "Ivan Bykovich" is strikingly reminiscent of the liberation of water and cattle from the rock in Rig Veda. Both events happened after the victory of the solar hero, i.e. after the end of the total phase of a solar eclipse in our reconstruction. Notably the hymn indicates the Many and Bakhu mountains directly, practically describing the hieroglyph Ahet with two mountains and fire between them, that was just born.

The dragon fight myth of the Slavs is tracked in rites. A notable example is the wedding ceremony in which Ivanov and Toporov [8] showed that the groom and the bride are likened to the dragon fighter and his wife, the wedding loaf to the world tree, and the wedding itself to the marriage of the Sun. Here is a song from the bachelorette party [26]:

\section{Oh Smoke, Smoke River,}

\section{Between mountains Smoke passed}

Over Smoke - the rapid river -

\section{Kalinovy bridges paved}

Beams are of brushwood.

That no one along bridges go,

Along Kalinovys no one passes.

As Ivan will go along bridges,

As Mikhaylovich will pass

Behind him he leads Aksinya

Takes across Nikolaevna... 
Page 7 of 9

From the point of view of the solar eclipse, the song describes the river passing between Bakhu and Manu mountains. The solar hero only can be at the place that is why no one else can go along the bridges. And it means that the groom Ivan Michaylovich is likened to the dragon fighter and Aksinya Nikolaevna to his wife. The place itself is a site of a dragon fight. This interpretation produced the same conclusions as [8] with the difference that they were obtained through a new approach.

The wedding is the marriage of the Sun that is why the hypothesis that originally Slavs had a myth of antagonistic struggle of the Sun with the Serpent obtains one more evidence.

The dragon slayers can be tracked in toponyms as well. For example, Krak, the legendary founder of Krakow, the first capital of Poland, defeated the dragon of Wawel (Figure 6). Wawel Hill is located near the Vistula with the Royal Castle on top of it. Phonetic analysis showed that the word 'Wawel' comes from the root ${ }^{*} V e l-$, which means the god Veles - a snake or a dragon. At the same time, based on the same analysis, Krak is derived from the "mountains". It is reflected in opposition: Perun is at the top, in the mountains, and the Snake is down by the water, in this case, under the stone hill on the banks of the Vistula River.

The name Kyi, the eldest of the legendary brothers who founded $\mathrm{Kiev}$, is associated with the root ${ }^{*}$ kou-(forge) [28] that depicts him as a smith who defeated a serpent that dwelt near Kiev. He harnessed the serpent to a plow and plowed the Serpent's Walls to the Black Sea, where the serpent was killed. The Serpent's Walls are a system of defensive walls, built in the 2 century BC - 7 century AD mostly along the Dnepr River.

The evolution of this Slavic myth could be suggested as follows. Initially the Sun fought with the serpent in full accordance with the Egyptian myth. As weapons he used peruns (thunderbolts) - arrows, lightning, and stones. Over time, the Sun was replaced by Perun the god of Thunderstorm, also had a solar nature. And later Perun was replaced by solar heroes.

It is notable that legendary figures, such as the already mentioned Krak and Kyi were dragon slayers. They were ordinary mortals but were allowed to overcome the dragons in the fight. It comes from Ancient Egypt, where the leader of the country was a direct descendant of the god of the Sun. So the dragon could be slayed not by a mere mortal, but by a king or prince. At the beginning of religion, only the pharaohs possessed an immortal soul. That gave them the right to be dragon slayers. With the evolution of religion, every person started to possess an immortal soul. Therefore, during the period of the Slavic tribes in order to be a dragon slayer, one was required not only to have an immortal soul (as everyone had one) but also a relationship to the god of the Sun, which only leaders of countries had.

Thus, all three main ideas of the ancient Egyptians that was inspired by solar eclipses were recorded by Aymen [1], are reflected in the Slavic outlook: the myth of creation and the end of the world, slaying of the dragon and the solar nature of the head of state.

\section{Wholeness of views of the slavs}

Afanasyev, in his detailed work "The Poetic Outlook of Slavs about Nature", substantiated that "...Myths of world creation, its death and the universal flood are different poetic pictures of spring renewal of nature, views, arising in pictorial metaphors from the ancient language" [27]. The scheme of the myth: death of a solar hero - finding help - a victory over the forces of darkness (the serpent), was interpreted as an annual cycle. For example, the Brockhaus and Efron Encyclopedic Dictionary about the already mentioned legend of Krak wrote: "on the most accepted opinion, in this myth Krak served the personification of the sun, snake - of winter." Thus the legend describes the annual victory of the Sun over short winter days.

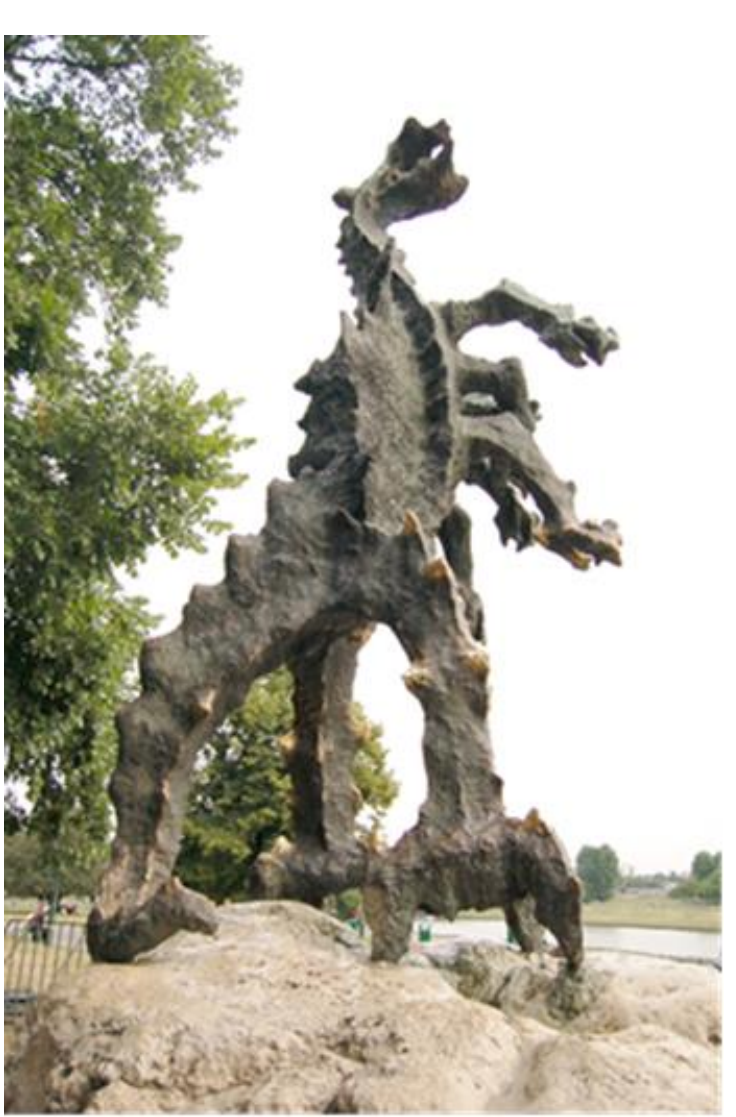

Figure 6: Wawel dragon. Photo by author

Linking dragon slaying with the seasons and annual rites was widespread in research. Let us take a typical example. M. V. Popovich described the parts of the annual cycle suggesting it for general IndoEuropean views. For winter he wrote:

"Evil forces kidnapped the sun from the sky, or an object of solar nature and plunged with it to the bottom of the ocean. Solar hero starts to duel with the evil force, he offers to the evil inclination a series of tests, one of which is immersion into the seabed. At this time, solar hero freezes the surface of the ocean, and while the evil force tries to get out from under the ice, saves the sun. During this deed the solar hero either dies or suffers other way from the sun gear" [28].

Considering the seasons in details he stated regarding summer:

"The complete triumph of solar inclination, winning of solar forces occurs on the summer solstice: the Sun is released, vegetative strengths are combined with fire ones maximally. But a disturbing motive weaves in this sensual hymn to victory: the solar hero dies from the sun gear, the day begins to decline, and the dark forces again stalk to the sun, to the world fire" [29, p. 120]. 
Page 8 of 9

This type of reasoning demonstrates inconsistency. Slavs celebrated the summer solstice on the most joyful summer holiday Kupala. Why did the death of the sun, even in the form of a solar hero, make the Slavs so happy? Why was the joy not dampened by the death of the main deity?

If we consider the myth as a description of a solar eclipse, the death of the solar hero and his victory over the forces of darkness afterwards are an inevitability (as was observed) and not scenic metaphors. The action on the ocean and uprising of the Sun from its bottom are repetitions of the ancient Egyptian myth. Thus, it is enough to separate the myth of the solar hero from the annual cycle and ceremonies, as both components find their inner meaning. Midsummer is a joyful longest day of the year and the epic about the solar hero is the story of a solar eclipse observed by ancestors.

In light of this interpretation, the death of the Sun becomes not a recurring annual event, but a very rarely occurring full of horror disaster. It is so rare, so unusual and dramatic that it is necessary to inform succeeding generations about it. The death of the Sun, and in extension the death of the whole world, is not cyclical but an extraordinary event. Thus, it is concluded that the ancient Slavs, so to speak, allowed the most important god - god of the Sun - to die not so often, not every year, but once in the life of a few generations, passing on the torch about how it happened to descendants with reverence. These stories have survived in the form of myths about dragons layers, about the creation and the end of the world.

In addition, there is another remarkable conclusion. What we call myth of creation, does not respond to creation in essence. In the beginning there was the ocean. What existed before that? First there was the ocean, and the Benu bird flew over it and landed on a rock (Egypt) [30]. First there was the ocean, and the duck carried over it in its beak a lump of land (the nomadic peoples of the Far North) [31]. And where did these birds, a rock or a lump of land come from? The myths give no answer to these questions. And not because people did not know or think about what existed before, but because these myths are a description of the observed event, a solar eclipse. The purpose of the myth is completely different: to tell how it all happened, and not how everything was created. Therefore, in this description in principle there are no questions about how Benu appeared, or where the Ocean came from. The myths of creation and of the end of the world are just descriptions that people observed during the eclipse. They are very pragmatic. The fear of death of the god of the Sun for his disappearance in the sky can be seen in the myth of the end of the world, but the story is still an accurate description. So it is possible to call the myths as creation and end of the world, but it is necessary to keep in mind that in practice no fundamental questions of the origin and death of the world were being addressed.

The proposed interpretation clarifies many facts, while others receive a satisfactory explanation. Predictions could be checked in further studies. And what is perhaps the most impressive is that the most ambitious astronomical phenomenon, the total solar eclipse, is not just reflected in the culture of the ancient Slavs but took a prime position in their outlook.

\section{Conclusions}

It is shown that the description of the solar eclipse took the main position in the Slavs outlook. It has been proven that the myths of creation and death of the world as well as myths and epics about dragon slayers are an accurate description of total solar eclipses.
As a result, meanings of many words such as 'Alatyr', and objects such as 'World tree ',' Island Buyan ', Kalinovy Bridge' have been clarified.

A proposed meaning for 'Smorodina River 'as' Dragon River is explained,

The connection of main Slavic myths with similar ones in ancient Egypt has been shown clearly. Since Slavic peoples are one of the branches of the Indo-European group, this connection has proven that the Indo-European tribes absorbed Egyptian knowledge before starting the resettlement of the world.

The method of investigation has been described in detail. It is expected that applying this method to other resources will provide fruitful archeoastronomical results. The resources should be linguistic, artifacts (such as Permian bronze casts [31]), and cultural (such as Abazin tales [32]) of different tribes and people around the world.

\section{Acknowledgements}

The author is grateful to KITION Planetarium and Observatory for the kind invitation to Cyprus to finish this first part of the proposed program, to prof. I. Charalambidou (University of Nicosia, Cyprus) for fruitful discussion and to J. Wiggins (Open Sky Software, Oregon) for his support.

\section{References}

1. Aymen Ibrahem (2014) Akhet - The Horizon of Heaven or something else?

2. Aymen Ibrahem (2014) The Wonders of the Sun! The Jordon Astronomical Society.

3. Illich-Svitych VM (1971) My Experience of comparison of Nostratic languages. Moscow.

4. Ivanov VV, Gamkrelidze TV (1984) Indo-European and the IndoEuropeans: A reconstruction and historical analysis of a proto-language and a proto-culture, Tbilisi state University, Georgia.

5. Barsov EV (1886) On the sea of Tiberias: Readings in Society of History and Russian Antiques. Moscow. For comparative analysis with other lists, look: V. S. Kuznetsova. Dualistic legends about the creation of the world in the East Slavic folk tradition. Novosibirsk, 1997.

6. Etnografichny zbirnyk (1914) Vydaje etnografichna komisija naukovogo tovarystva imeni Shevchenko. Carols and schedrivkas. Collected by Volodymyr Gnatiuk. Lviv. NB. Sometimes cited: Carols and songs. Lvov.

7. Maykov L (1869) Great Russian Spells. St.Petersburg.

8. Ivanov VV, Toporov VN (1974) Research in the field of Slavic antiquities: Lexical and phraseological questions of texts reconstruction, Moscow.

9. Nadezhdin NI (1853) Vestnik Imperatorskago Russkago Georgievskago Obshchestva.

10. Romanov ER (1891) Belorussian Collection: Conspiracies, apocrypha, spiritual poems. Vitebsk.

11. Afanasyev AN (1984) Koschej the Deathless, Russian folk tales, Moscow.

12. van der Waerden (1974) Science Awakening II. Springer, Zurich.

13. Melnikov-Pechersky PI (1842) Solar eclipse visible in Russia up to the XVI century. St.-Petersburg.

14. Afanasyev AN (1865) The Poetic Outlook of Slavs about Nature. Moscow 1: 269.

15. Ibrahem AM (2001) Unlocking the Oldest Riddle in Histroy: The True Nature of the Egyptian Pyramids. Astronomy Digest.

16. Buslaev FI (1861) Historical Anthology of Church-Slavic and Ancient Russian Languages, Moscow. 
17. Afanasyev AN (1865) The Poetic Outlook of Slavs about Nature. Moscow 1: 263.

18. Hilferding AF (1871) Onega epics recorded by in summer, Moscow.

19. Ibid, vol II, 148 .

20. Onchukov NE (1904) Pechora epics St.Petersburg.

21. Wallis Budge EA (1895) The Book of the Dead: The Papyrus of Ani in the British Museum.

22. Ivan Bykovich (1984) Russian folk tales. (3rd edn) Afanasyev AN, Moscow.

23. Propp VY (2000) Russian fairy tale, Moscow.

24. Dal VI (1991) Explanatory Dictionary of the Live Great Russian language.

25. Griffith RTH (1896) The Rig Veda, Wiltshire.
26. Gulyaev SI (1848) Ethnographic essays of the South Siberia, Petersburg.

27. Afanasyev AN (1867) The Poetic Outlook of Slavs about Nature. Moscow.

28. Popovich MV (1985) Worldview of the Ancient Slavs, Kiev.

29. Rundle Clark RT (1991) Myth and Symbol in Ancient Egypt. Thames and Hudson Publishers, New York.

30. Kuksin C (2008) Personal communication by the director of the Museum of Nomadic Culture Moscow, in Kyzyl.

31. Prokofyev A (2011) Solar Eclipses in Slavic Shamanism. Report at the III Open Meeting of Amateurs of Astronomy in Krasnograd, Krasnograd.

32. Prokofyev A (2012) Solar Eclipses in Abazines Tales. Report at the IV Open Meeting of Amateurs of Astronomy in Krasnograd, Krasnograd. 